\title{
Amount of Plant Foods Eaten and Sexual Differences in Feeding among Wild Chimpanzees (Pan troglodytes) of Kanyawara Community
}

\author{
Moses Chemurot, Gilbert Isabirye-Basuta, and Eric Sande \\ Department of Biological Sciences, Makerere University, P.O. Box 7062, Kampala, Uganda \\ Correspondence should be addressed to Moses Chemurot, moseschemurot@gmail.com
}

Received 20 April 2012; Accepted 10 June 2012

Academic Editors: S. P. Henzi, S. P. Lambeth, D. Park, and A. Ramirez-Bautista

Copyright ( $\odot 2012$ Moses Chemurot et al. This is an open access article distributed under the Creative Commons Attribution License, which permits unrestricted use, distribution, and reproduction in any medium, provided the original work is properly cited.

\begin{abstract}
The amount of plant foods eaten and sexual differences in food intake among chimpanzees in Kibale Forest was investigated between July 2007 and January 2008. Continuous focal animal sampling was used to collect data on the diet, number, and duration of feeding bouts of 18 individuals of the Kanyawara chimpanzee community. Chimpanzees utilized 42 plant species for fruits, leaves, and piths. Among plant parts eaten, fruits contributed the greatest percentage of fresh weight (18) in the diets compared to leaves (5.1) and piths (3.6). The duration of feeding bouts varied, ranging from 1.5 to 45.8 minutes. When Mimusops bagshawei fruits were eaten, the numbers of feeding bouts per chimpanzee per day were high compared to when they were not. While our study agrees with previous studies that females spend more time feeding per day, it shows that the long feeding time among females does not translate to increased food weight. We suggest that the social role of females in taking care of the young and their attention being taken up by this role while feeding and fears associated with male presence is the reason for long feeding time among females.
\end{abstract}

\section{Introduction}

Food availability varies both in time and space and there are reports of seasonal and dramatic interannual variations in the sources and quantities of food [1-4]. As a result, the diets of primate species are expected to change with food availability.

The diet of wild chimpanzees is highly diverse and includes fruits, blossoms, barks of trees, leaves, and leaf buds. Although their diet includes many vegetables, they prefer fruit [5-10], and they supplement with a variety of insects, birds' eggs, birds [11], and small to medium-sized mammals [11-15].

Chimpanzee diet is more diverse when food is scarce. During this time stems, barks, underground storage organs and insects are eaten [11]. Consumption of Terrestrial Herbaceous Vegetation (THV) by the Kanyawara community chimpanzees increases as an alternative (fallback) resource when fruit is scarce [16]. Kanyawara chimpanzees preferentially consume arboreal drupes when available $[17,18]$. When drupes are not available, figs are eaten in spite of their low sugar content compared with drupes [19].

Studies using feeding duration have shown that female chimpanzees spend more time feeding than males [20-22]. Although several studies on chimpanzee feeding ecology have been undertaken at different study sites: in Tanzania, [13], and Uganda [7, 9, 17, 23-25], no study has systematically estimated the weight of food eaten by wild chimpanzees or assessed the contribution of each plant food to total food intake per day. Information on weight of food eaten by different sexes of chimpanzees can help us understand sexual differences in feeding time. In this paper, we estimate food weight eaten and evaluate sexual differences in food intake. We evaluate food weight eaten per bout for each 
plant species. Three independent measures of food intake are employed: feeding bout duration, food weight per bout, and food weight per day.

\section{Materials and Methods}

2.1. Study Area. This study was conducted at Kanyawara study site, in Kibale National Park in Western Uganda $\left(0^{\circ}\right.$ $13^{\prime}$ to $0^{\circ} 41^{\prime} \mathrm{N}$ and $30^{\circ} 19^{\prime}$ to $30^{\circ} 32^{\prime} \mathrm{E}$ ) near the base of the Rwenzori Mountains.

2.1.1. Observational Units. The study used the Kanyawara chimpanzee community which has been studied since $1983[2,15,18,26]$. Since the community is habituated, individual identification [27] and closer observations were possible.

We observed 18 chimpanzees: 5 adult males (2 high ranking, 2 middle ranking, and 1 low ranking), 3 subadult males, 7 adult females, and 3 subadult females. Adult chimpanzees were defined as individuals above 15 years of age (for known-age males) or those that have had their first birth (for females). Subadults were defined as individuals above 11 years and less than 16 (for females, they must have never had their first birth).

2.1.2. Data Collection Methods. Data were collected from July 2007 to January 2008 using focal observations which were made targeting one chimpanzee per day that was followed for the whole day ( $6 \mathrm{am}$ to $7 \mathrm{pm})$. The activities recorded were feeding (food species, feeding rates, and feeding bouts) rest and travel. One-minute focal observations were made after every five minutes or opportunistically to record feeding rates. To ensure that the data were reliable, two independent observers recorded feeding rates of the same food items and same focal individuals at the same time for two months. A feeding bout ended when the target chimpanzee finished eating, began to move, switched food type, or started grooming or resting even if the food was retained in the hand or mouth for more than 4 minutes without any manipulation.

2.1.3. Estimation of Food Weight. Fresh plant parts of the type eaten were collected and weighed. In cases where only part of the food item was eaten, leftovers during feeding and uneaten foods were collected and weighed. To ensure that the sample obtained was the same weight as the sample eaten, food items were observed carefully and matched to the size, colour, and any other physical characteristics of items that had been eaten, as closely as possible.

2.2. Data Analysis. The fresh weight of the food eaten per feeding bout was calculated by multiplying the feeding rate by the length of the feeding bout. Weights of food eaten per day were estimated using full day observation data when the focal individuals were in clear view throughout. Kruskal-Wallis tests were used to test for differences in food consumption among adult and subadult chimpanzees and males and females. Paired samples $t$-tests were used to
TABle 1: Average number of feeding bouts per day (no. bouts), average weight of food eaten per feeding bout (Wgt/bout $(\mathrm{g})$ ), and average weight of food eaten per day (Wgt/day $(\mathrm{g})$ ) irrespective of food type and season.

\begin{tabular}{lcccc}
\hline Age group & No. of bouts & Wgt/bout $(\mathrm{g})$ & Wgt/day $(\mathrm{g})$ & $n$ \\
\hline Adult female & $11.3 \pm 1.4$ & $584.1 \pm 62.3$ & $6019.5 \pm 406.8$ & 3 \\
Adult male & $12 \pm 1.4$ & $572.8 \pm 86.3$ & $6332.6 \pm 647.2$ & 3 \\
Sub-adult male & $15.6 \pm 2.1$ & $435.3 \pm 136.2$ & $6473.9 \pm 172.9$ & 3 \\
Sub-adult female & $15.4 \pm 0.8$ & $460.6 \pm 49.2$ & $6824.9 \pm 607.5$ & 2 \\
\hline
\end{tabular}

Where $n=$ number of individuals sampled.

compare food consumption during different times of the day. All the statistical tests used were two-tailed.

\section{Results}

3.1. Food Species and Feeding Rates. Chimpanzees utilized 42 plant species for fruit, leaves, and piths. Fruits on average contributed the greatest percentage food weight (18\%) compared with leaves $(5.1 \%)$ and piths $(3.6 \%)$. For each the percentage weight contributions varied widely, for example, in fruits it ranged from $1.8 \%$ for Ficus urceolaris to $41.5 \%$ for Ficus natalensis.

3.1.1. Feeding Bouts and Feeding Durations. The duration of feeding bouts per chimpanzee ranged from 1.5 to 45.8 minutes with a mean length of $24 \pm 0.0$ minutes $(n=934$, feeding bouts), (Table 2). Subadults of both sexes generally had significantly greater numbers of feeding bouts per day than adults of both sexes (Table 1$)$, (chi-square $=7.4$, $P<0.01, n=31$ days, Kruskal-Wallis test).

Mean feeding bout lengths and mean fresh weights of food ingested per feeding bout varied with plant species (Table 2). Some plant species such as figs contributed significantly to the total food intake per day while others had a very small contribution.

Mimusops bagshawei fruits influenced the numbers of feeding bouts per day, the numbers of feeding bouts being higher when $M$. bagshawei fruit was part of the diet than when it was not $(12 \pm 0.7$ bouts when $M$. bagshawei was absent and $17 \pm 1.7$ when present in the diet). However, less food was eaten per bout and per day when $M$. bagshawei fruit was part of the diet (food weight per bout $539.5 \pm 35.1 \mathrm{~g}$ when M. bagshawei was absent and $393.9 \pm 120.5 \mathrm{~g}$ when present; food weight per day $6607.7 \pm 413.4 \mathrm{~g}$ when $M$. bagshawei was absent and $5826.3 \pm 877.4 \mathrm{~g}$ when present).

3.1.2. Food Weight Eaten and Time of Day. Chimpanzees ate significantly greater weights of food in the morning than during afternoon and evening (morning and afternoon; $t=$ $3.429, \mathrm{df}=237, P<0.01$ : morning and evening; $t=2.157$, $\mathrm{df}=237, P<0.05$ : afternoon and evening; $t=-1.656$, $\mathrm{df}=249, P>0.05$, paired samples $t$-test).

3.1.3. Food Weight Eaten, Age, and Chimpanzee Sex. Subadult and adult chimpanzees of both sexes ate weights of food per 
TABLE 2: Plant species and their contribution to total food intake when available and eaten.

\begin{tabular}{|c|c|c|c|c|c|}
\hline Plant species & $\%$ in diet & $\begin{array}{l}\text { Mean feeding time (minutes) } \\
\text { per bout }\end{array}$ & $\begin{array}{l}\text { Mean feeding rate } \\
(\mathrm{g} / \mathrm{min})\end{array}$ & $\begin{array}{l}\text { Mean food weight per bout } \\
\text { (grams) }\end{array}$ & Parts eaten \\
\hline Ficus brachypoda & 82 & 6.5 & 5223.4 & $\mathrm{~F}$ & \\
\hline Ficus dawei & 33.6 & 43 & 5.2 & 1136.3 & $\mathrm{~F}$ \\
\hline Secamone africana & 43 & 1 & 1131.8 & F & \\
\hline Cordia millenii & 25.7 & 45.8 & 2.5 & 1031.3 & $\mathrm{~F}$ \\
\hline Urera & 33.7 & 20.1 & 11.8 & 915.6 & $\mathrm{~F}$ \\
\hline Ficus vallis-choudae & 13.9 & 16.6 & 1.1 & 812.5 & $\mathrm{~F}$ \\
\hline Celtis africana & 23.9 & 20 & 14.5 & 726.5 & $\mathrm{~L}, \mathrm{~B}$ \\
\hline Ficus brachylepis & 35.9 & 32.8 & 2.6 & 720 & $\mathrm{~F}$ \\
\hline Ficus cyathistipula & 18.1 & 18.1 & 3.4 & 617.8 & $\mathrm{~F}$ \\
\hline Ficus natalensis & 41.5 & 40.1 & 13.4 & 616.3 & $\mathrm{~F}$ \\
\hline Ficus ottonofolia & 23 & 26.3 & 16.1 & 609.1 & $\mathrm{~F}$ \\
\hline Cyperus papyrus & 57 & 10.1 & 575.7 & $\mathrm{P}$ & \\
\hline Ficus capensis & 34 & 37.6 & 4.9 & 573.8 & $\mathrm{~F}$ \\
\hline Phytolacca dodecandra & 15.6 & 3.8 & 561.9 & F & \\
\hline Cordia abyssinica & 8.2 & 19.7 & 15.4 & 347.4 & $\mathrm{~F}$ \\
\hline Lepistemon welwietschei & 2.5 & 16.5 & 16.2 & 337.6 & $\mathrm{~L}$ \\
\hline Ficus exasperatae & 19.4 & 26.1 & 8.8 & 290.8 & $\mathrm{~F}, \mathrm{~L}$ \\
\hline Ficus stipulifera & 7 & 4.3 & 289.6 & F & \\
\hline Mimusops bagshawei & 17.5 & 26.7 & 5.9 & 237.9 & $\mathrm{~F}$ \\
\hline Triumfetta tomentose & 7.1 & 12.7 & 21.8 & 237.3 & $\mathrm{~L}$ \\
\hline Urtica massaica & 8.7 & 9.8 & 6.3 & 236.6 & $\mathrm{~F}, \mathrm{~L}$ \\
\hline Acanthus pubescens & 8.4 & 7.8 & 30.6 & 224 & $\mathrm{P}$ \\
\hline Linociera johnsonii & 4 & 7.1 & 210.6 & $\mathrm{~F}$ & \\
\hline Aframomum sp. & 3.5 & 10.1 & 12.4 & 206.4 & $\mathrm{P}$ \\
\hline Uvariopsis congensis & 9.9 & 6.5 & 1.9 & 184.8 & $\mathrm{~F}$ \\
\hline Ficus thonningii & 2 & 11 & 48.2 & 148.3 & $\mathrm{~F}$ \\
\hline Myrianthus arboreus & 8.4 & 7.2 & 2 & 146.9 & $\mathrm{~F}, \mathrm{~L}$ \\
\hline Trichilia splendid & 3.2 & 5.7 & 11.2 & 115.3 & $\mathrm{~L}$ \\
\hline Antiaris toxicaria & 1.7 & 4 & 10.3 & 80.5 & $\mathrm{P}, \mathrm{L}$ \\
\hline Teclea nobilis & 4.9 & 18.6 & 23.3 & 77.8 & $\mathrm{~F}$ \\
\hline Bosqueia phoberos & 6.3 & 12.8 & 22.7 & 75.1 & $\mathrm{~L}$ \\
\hline Piper capensis & 0.9 & 3 & 23 & 58.1 & $\mathrm{P}$ \\
\hline Aneilema sp. & 0.1 & 10 & 7.3 & 49.8 & $\mathrm{~L}$ \\
\hline Ficus urceolaris & 1.8 & 4.2 & 17 & 46.9 & $\mathrm{~F}, \mathrm{~L}$ \\
\hline Illigera sp. & 4 & 16 & 33.6 & $\mathrm{~L}$ & \\
\hline Chaetacme aristata & 2.8 & 7.8 & 26.3 & 31.6 & $\mathrm{~L}, \mathrm{~B}$ \\
\hline Celtis durandii & 4.1 & 22.2 & 26.3 & 31.6 & $\mathrm{~F}$ \\
\hline Acalypha & 0.2 & 2.5 & 7.3 & 27.7 & $\mathrm{~L}$ \\
\hline Marantochloa & 4 & 5.8 & 23.2 & $\mathrm{P}$ & \\
\hline Rubus apetalus & 1.5 & 24.3 & 21.9 & $\mathrm{~F}$ & \\
\hline Pterygota & 0.4 & 2 & 3.7 & 21.5 & $\mathrm{~L}$ \\
\hline Rubia cordifolia & 22 & 3.3 & 13.7 & $\mathrm{~L}$ & \\
\hline
\end{tabular}

The plant species are arranged in descending order of mean weight of food eaten per bout (\% contribution by each plant species was estimated by calculating the average wet weight of each food item eaten per day for all food items during full day follows and converting the value obtained as a percentage of total weight of food eaten per day). Empty cells imply that data was not recorded for full day.

Where F: fruit, L: leaves, B: bark, P: pith, and g/min: grams of food ingested per minute. 
TABLE 3: Average total daily activity time (\%) allocated to different activities among adult and subadult chimpanzees.

\begin{tabular}{lccccc}
\hline Activity & Adult female & Adult male & Sub-adult male & Sub-adult female & Average \\
\hline Feeding & 58.4 & 45.7 & 56.1 & 59.4 & 54.9 \\
Resting & 32.1 & 44.6 & 26.9 & 25.4 & 32.3 \\
Traveling & 9.5 & 9.7 & 17 & 15.1 & 12.8 \\
\hline
\end{tabular}

feeding bout and per day that did not vary significantly (food weight per bout: chi-square $=2.6, P>0.05, n=32$ days, Kruskal-Wallis test), (food weight per day: chi-square $=0.8$, $P>0.05, n=32$ days, Kruskal-Wallis test).

There was no significant difference in neither the weight of food eaten nor the number of feeding bouts between sexes (food weight per bout; rs $=0.020, P>0.05, n=798$ observations, Spearman's rank correlation test), (food weight per day; $r s=0.042, P>0.05, n=32$ days, Spearman's rank correlation test). However, adult females spent more time feeding ( $58.4 \%$ of their waking hours) compared to adult males ( $45.7 \%$ of their waking hours) who spent more time resting and traveling per day (Table 3).

\section{Discussion}

Chimpanzees of all sexes and age groups fed on 42 plant species for fruits, leaves, and piths at varying rates. Feeding on different plant species at different rates may be attributed to differences in nutrient levels and benefits such as medication associated with feeding on some plant foods [28]. Chimpanzees consumed more weight of food during feeding bouts on fruit compared with all other plant parts. Chimpanzees also spent more time feeding on fruits during each feeding bout. These findings agree with earlier reports [5-10] which using data on feeding time noted that chimpanzees have a preference for fruits. Specifically, Kanyawara chimpanzees prefer arboreal drupes [17, 18], although figs play a vital role by supplying nutrients when drupes are not available because of their irregular fruiting habits. High contributions to total food intake per day by figs can be attributed to their availability throughout the year and being available even when no other fruits are available in the forest [7]. Fruit preference might be attributed to sugar levels which are high in fruits compared to leaves and piths. Piths and leaves contributed smaller fresh weights to total food weight per day compared with fruits because piths and leaves have low sugar and protein [17] and are high in hemicellulose and cellulose.

There were no statistically significant age-group differences in weights of food eaten per feeding bout and per day. Subadults of both sexes had significantly greater numbers of feeding bouts per day compared with adults probably because they have smaller guts that would get filled faster and got emptied quicker than in adults. Additionally, subadults in primates are more playful compared with adults [29] which results in interruption of their feeding regimes.

During days when M. bagshawei fruits were eaten, the average numbers of feeding bouts per day were high but the weight of food eaten per feeding bout and per day was low compared with when it was not included in the diet.
The high number of feeding bouts when M. bagshawei fruits were included in the diet may be attributed to preference for its fruits by Kanyawara chimpanzees [17, 18]. Kanyawara chimpanzees ate less food per feeding bout and day when $M$. bagshawei was included in the diet probably due to the highenergy content of its fruits compared to figs [19]. Eating a small weight of $M$. bagshawei fruits can supply the energy that can be supplied by a greater weight of figs. Whether the benefits of feeding on varying weights of different plant foods per day lies in the nutritional contributions of the plant species involved or taste, this study provides a strong evidence that some food items such as M. bagshawei can influence feeding regimes. As such, they demonstrate the best form of influence of food type on feeding behavior. We expect similar trends to be widespread in other primate species.

In agreement with previous studies [20-22], our study showed that female chimpanzees spent on average more time feeding per day compared with males. However, the long feeding time among females did not translate to feeding on more food weights per day. We attribute this to the social role of females taking care of the young [30], their attention being taken up by this role while feeding and fears associated with male presence. The long feeding times per day by females may be to compensate for feeding time lost as a result of these disruptions.

Our study for the first time quantifies weights of food eaten by wild chimpanzees. While our study agrees with previous studies that females spend more time feeding per day, our work shows that the long feeding time among females does not translate to increased food intake.

\section{Acknowledgments}

Kibale Chimpanzee Project (KCP) provided funds for this study of which the authors are thankful. The authors are also thankful to KCP Manager, Dr. Emily Otali, and field assistants (F. Mugurusi, J. Sande, S. Musana, J. Kyomuhendo, C. Irumba, K.Wilberforce, J. Japan, and R. Musinguzi) for guidance and assistance during fieldwork.

\section{References}

[1] A. Whiten and E. M. Widdowson, Foraging Strategies and Natural Diet of Monkeys, Apes and Humans, Oxford Science Publications, New York, NY, USA, 1992.

[2] R. W. Wrangham, C. A. Chapman, A. P. Clark-Acardi, and G. Isabirye-Basuta, "Socioal ecology of Kanyawara chimpanzees: implications for understanding the costs of great ape groups," in Great Apes Societies, T. Nishida, Ed., Cambridge University Press, Cambridge, UK, 1992. 
[3] C. A. Chapman, R. W. Wrangham, and L. J. Chapman, "Ecological constraints on group size: an analysis of spider monkey and chimpanzee subgroups," Behavioral Ecology and Sociobiology, vol. 36, no. 1, pp. 59-70, 1995.

[4] R. W. Wrangham, N. L. Conklin-Brittain, and K. D. Hunt, "Dietary response of chimpanzees and cercopithecines to seasonal variation in fruit abundance. I. Antifeedants," International Journal of Primatology, vol. 19, no. 6, pp. 949-970, 1998.

[5] M. C. Ghighilieri, The Chimpanzees of Kibale Forest. A Field Study of Ecology and Social Structure, Columbia University Press, New York, NY, USA, 1984.

[6] T. Kano, The Last Ape. Pygmy Chimpanzee Behavior and Ecology, Stanford University Press, 1986.

[7] G. Isabirye-Basuta, "Feeding ecology of chimpanzees in the Kibale Forest, Uganda," in Understanding Chimpanzees, P. Heltne and L.A . Marquardt, Eds., pp. 116-127, Harvard University Press, Cambridge, Mass, USA, 1989.

[8] T. Nishida, "The chimpanzees of the mahale mountains. Sexual and life history strategies," International Journal of Primatology, vol. 12, no. 6, 1991.

[9] N. E. Newton-Fisher, "The diet of chimpanzees in the Budongo Forest Reserve, Uganda," African Journal of Ecology, vol. 37, no. 3, pp. 344-354, 1999.

[10] C. Boesch and H. Boesch-Achermann, The Chimpanzees of Tai Forest. Behavioral Ecology and Evolution, Oxford University Press, Oxford, UK, 2000.

[11] J. Goodall, The Chimpanzees of Gombe. Patterns of Behaviour, The Belknap Press of Harvard University Press, Cambridge, Mass, USA, 1986.

[12] A. Suzuki, "Carnivority and cannibalism observed among forest-living chimpanzees," The Anthropological Society of Nippon, vol. 79, pp. 30-48, 1971.

[13] R. W. Wrangham, "Feeding behaviour of chimpanzees in Gombe National Park, Tanzania," in Primate Ecology, pp. 503538, Academic Press, London, UK, 1977.

[14] T. Nishida, S. Uehara, and R. Nyundo, "Predatory behavior among wild chimpanzees of the mahale mountains," Primates, vol. 20, no. 1, pp. 1-20, 1979.

[15] I. C. Gilby and R. W. Wrangham, "Risk-prone hunting by chimpanzees (Pan troglodytes schweinfurthii) increases during periods of high diet quality," Behavioral Ecology and Sociobiology, vol. 61, no. 11, pp. 1771-1779, 2007.

[16] R. K. Malenky and R. W. Wrangham, "A quantitative comparison of terrestrial herbaceous food consumption by Pan paniscus in the Lomako Forest, Zaire, and Pan troglodytes in the Kibale Forest, Uganda," American Journal of Primatology, vol. 32, no. 1, pp. 1-12, 1994.

[17] R. W. Wrangham, N. L. Conklin, C. A. Chapman, and K. D. Hunt, "The significance of fibrous foods for Kibale Forest chimpanzees," Philosophical Transactions of Royal Society of London B, vol. 334, no. 1270, pp. 171-178, 1991.

[18] M. Thompson, Endocrinology and ecology of wild female chimpanzee reproduction [Ph.D. thesis], Department of Anthropology, Harvard University, Cambridge, Mass, USA, 2005.

[19] N. L. Conklin and R. W. Wrangham, "The value of figs to a hind-gut fermenting frugivore: a nutritional analysis," Biochemical Systematics and Ecology, vol. 22, no. 2, pp. 137151, 1994.

[20] J. D. Bygott, Agonistic behavior and dominance in wild chimpanzees [Ph.D. dissertation], Cambridge University, 1974.

[21] R. W. Wrangham, The behavioural ecology of chimpanzees in Gombe National Park, Tanzania [Ph.D. thesis], University of Cambridge, 1975.
[22] K. H. Farmer, H. M. Buchanan-Smith, and A. Jamart, "Behavioral adaptation of Pan troglodytes troglodytes," International Journal of Primatology, vol. 27, no. 3, pp. 747-765, 2006.

[23] R. W. Wrangham, N. L. Conklin, G. Etot et al., "The value of figs to chimpanzees," International Journal of Primatology, vol. 14, no. 2, pp. 243-256, 1993.

[24] M. Chemurot, Food Consumption and Rest Time in Chimpanzees (Pan Troglodytes) of Kanyawara Community [Unpublished M.S. thesis], Makerere University, Kibale National Park, Uganda, 2009.

[25] N. E. Newton-Fisher, V. Reynolds, and A. J. Plumptre, "Food supply and chimpanzee (Pan troglodytes schweinfurthii) party size in the Budongo Forest Reserve, Uganda," International Journal of Primatology, vol. 21, no. 4, pp. 613-628, 2000.

[26] G. Isabirye-Basuta, The ecology and conservation status of the chimpanzee (Pan troglodytes Blumenbach) in Kibale Forest, Uganda [Ph.D. thesis], Makerere University, Kampala, Uganda, 1990.

[27] C. A. Chapman and R. W. Wrangham, "Range use of the forest chimpanzees of kibale: implications for the understanding of chimpanzee social organization," American Journal of Primatology, vol. 31, no. 4, pp. 263-274, 1993.

[28] M. A. Huffman, "Current evidence for self-medication in primates: a multidisciplinary perspective," Yearbook of Physical Anthropology, vol. 40, pp. 171-200, 1997.

[29] R. Fagen, "Primate juveniles and primate play," in Juvenile Primates, M. E. Periera and L. A. Fairbanks, Eds., pp. 182-196, Oxford University Press, Oxford, UK, 1993.

[30] H. Pontzer and R. W. Wrangham, "Ontogeny of ranging in wild chimpanzees," International Journal of Primatology, vol. 27, no. 1, pp. 295-309, 2006. 

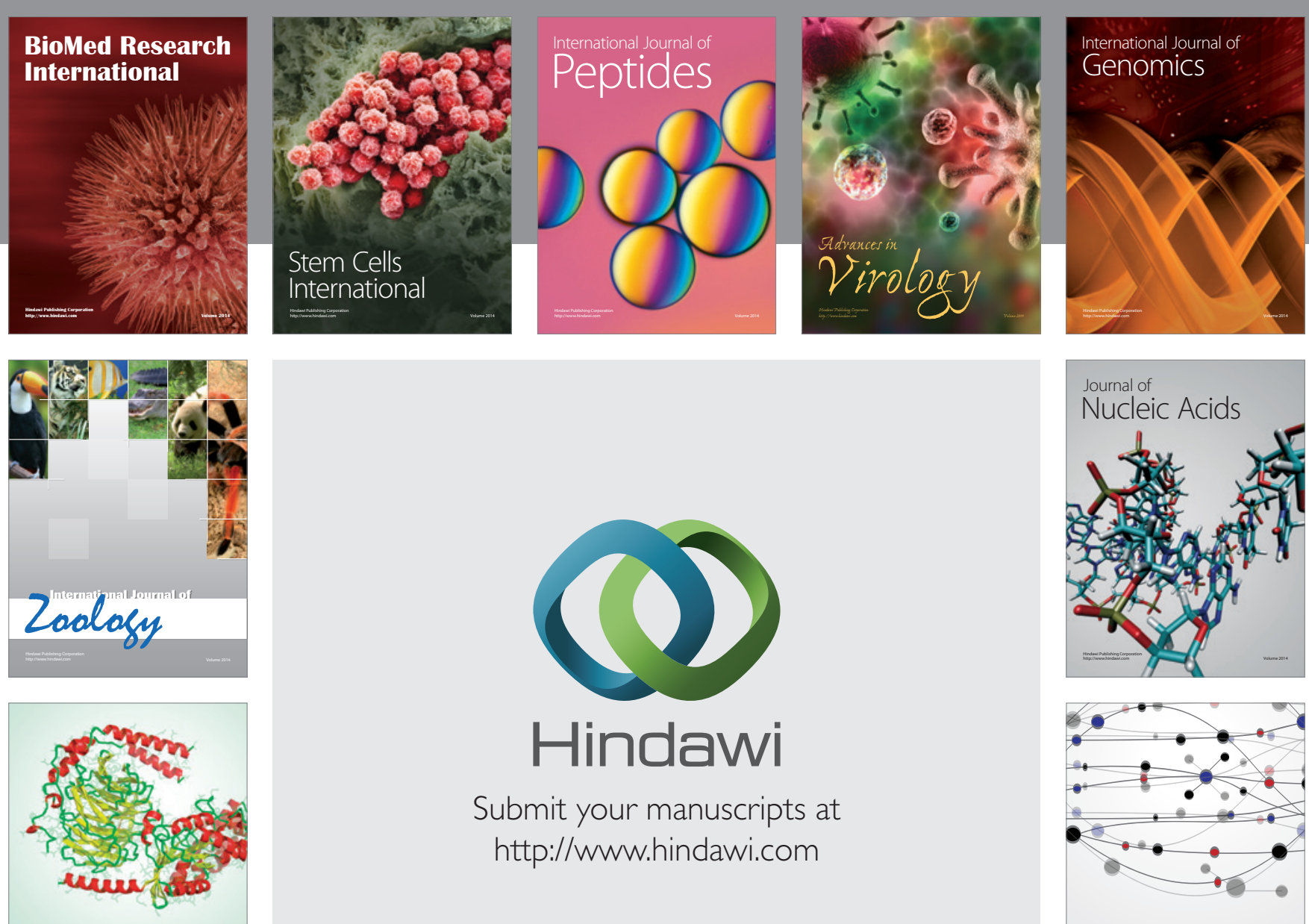

Submit your manuscripts at

http://www.hindawi.com

Signal ${ }^{\text {Jumal }}$ Transduction
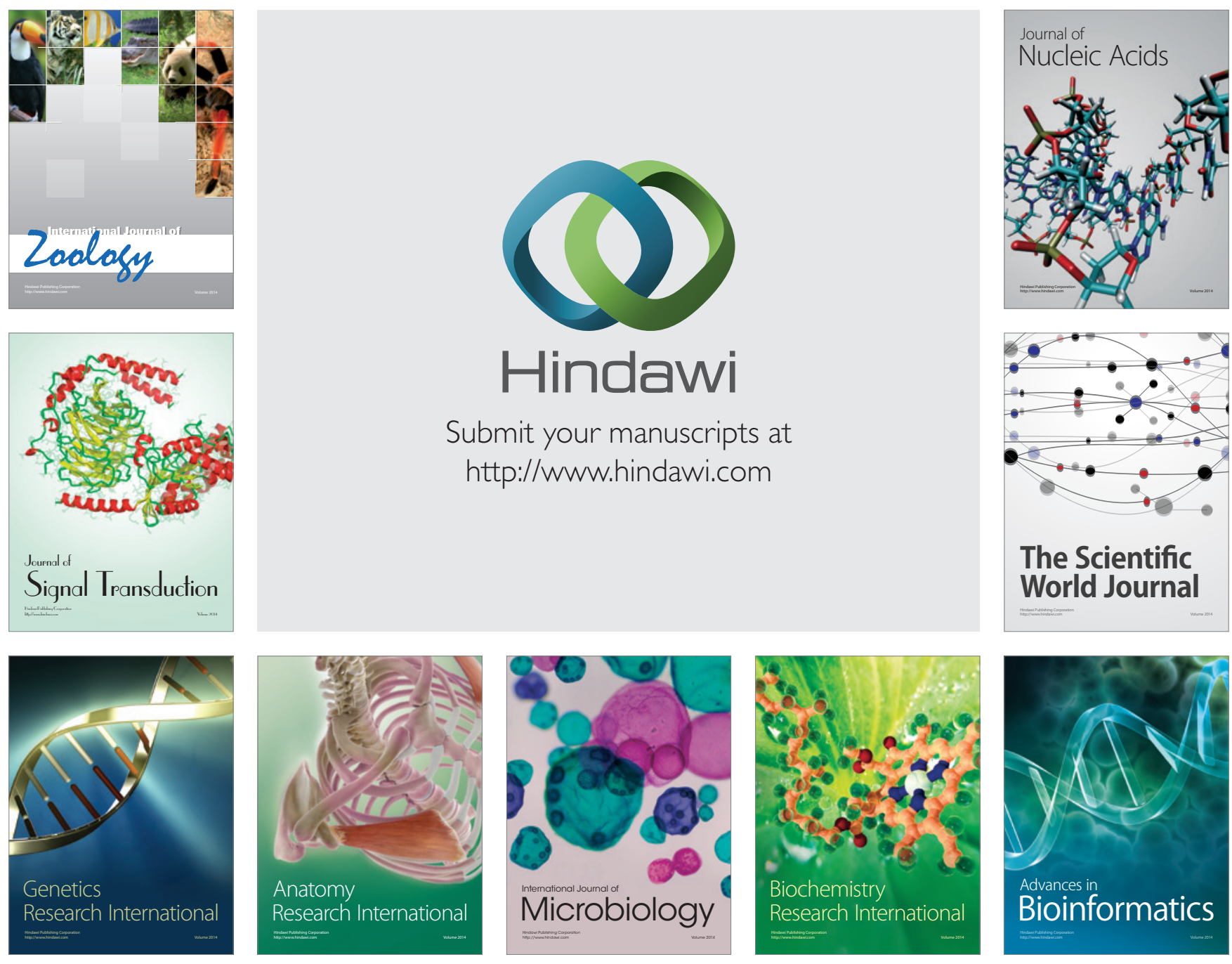

The Scientific World Journal
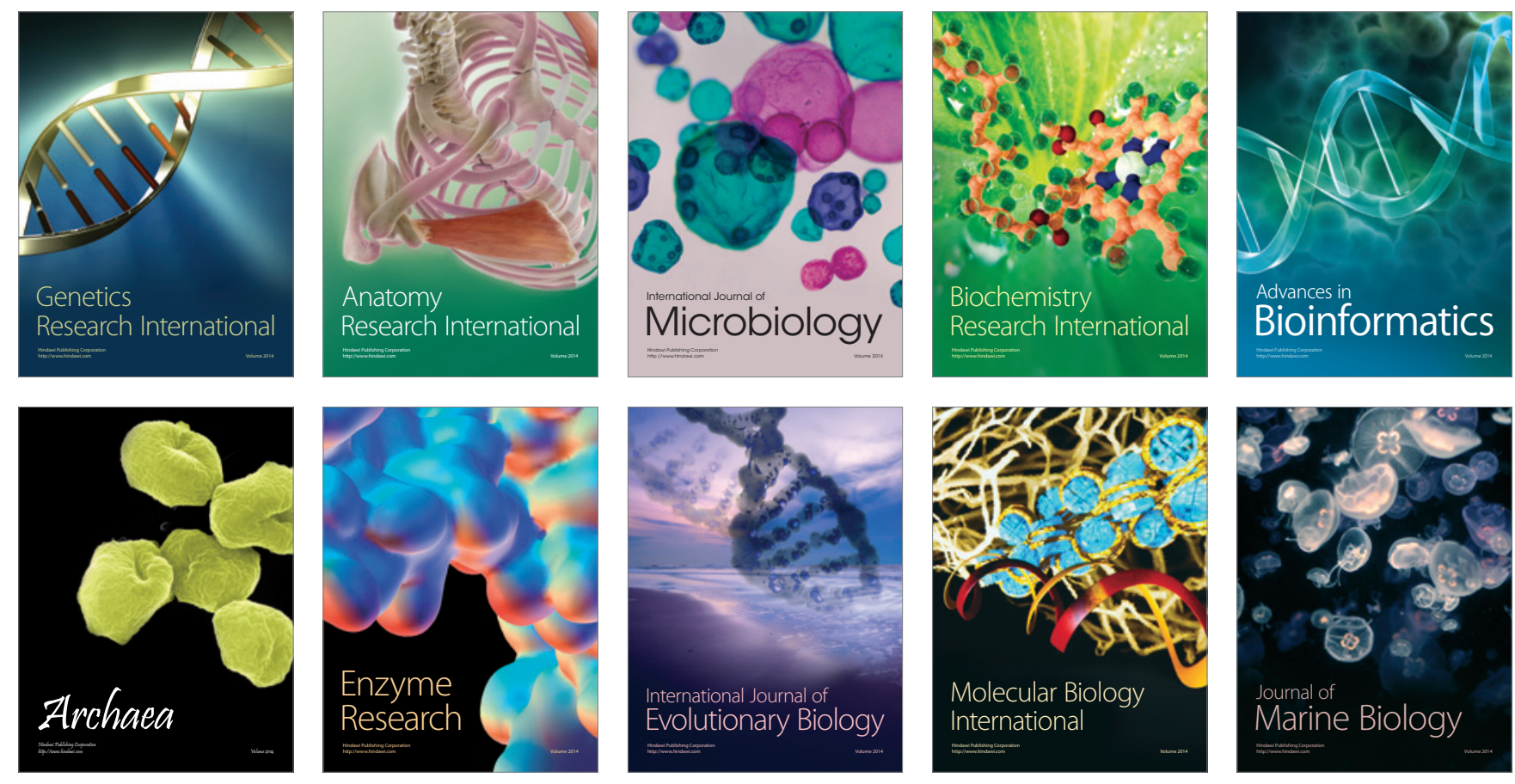